Management of 477 episodes of deliberate self poisoning in each study centre. Values are numbers (percentages) of patients

\begin{tabular}{|c|c|c|c|c|c|}
\hline $\begin{array}{l}\text { Centre (No of } \\
\text { episodes) }\end{array}$ & $\begin{array}{l}\text { Discharged from } \\
\text { accident and } \\
\text { emergency } \\
\text { department }\end{array}$ & $\begin{array}{l}\text { Discharged from } \\
\text { accident and emergency } \\
\text { department without } \\
\text { psychosocial } \\
\text { assessment }\end{array}$ & $\begin{array}{c}\text { Received psychosocial } \\
\text { assessment }\end{array}$ & $\begin{array}{c}\text { Admitted to } \\
\text { psychiatric ward }\end{array}$ & Followed up* \\
\hline Leeds (101) & $18(18)$ & $15(15)$ & $65(65)$ & $6(6)$ & $\begin{array}{l}46(45), \text { general practitioner } \\
16 \text { (16), deliberate self harm team } \\
28 \text { (28), psychiatric services } \\
10(10) \text {, alcohol services }\end{array}$ \\
\hline Leicester (111) & $61(55)$ & $23(21)$ & 76 (68) & $18(16)$ & $\begin{array}{l}50(45), \text { general practioner } \\
12(11), \text { deliberate self harm team } \\
44(40) \text {, psychiatric services } \\
2(2) \text {, alcohol services }\end{array}$ \\
\hline Manchester (100) & 71 (71) & $46(46)$ & $36(36)$ & $11(11)$ & $\begin{array}{l}67 \text { (67), general practitioner } \\
0 \text {, deliberate self harm team } \\
31 \text { (31), psychiatric services } \\
1 \text { (1), alcohol services }\end{array}$ \\
\hline Nottingham (165) & $53(32)$ & $42(25)$ & $80(48)$ & $13(8)$ & $\begin{array}{l}98 \text { (59), general practitioner } \\
14 \text { (8), deliberate self harm team } \\
43 \text { (26), psychiatric services } \\
6 \text { (4), alcohol services }\end{array}$ \\
\hline All centres (477) & $203(43)$ & $126(26)$ & 257 (54) & $48(10)$ & $\begin{array}{l}261 \text { (55), general practitioner } \\
42 \text { (9), deliberate self harm team } \\
146 \text { (31), psychiatric services } \\
19 \text { (4), alcohol services }\end{array}$ \\
\hline
\end{tabular}

${ }^{*}$ Nine episodes were followed up by a variety of agencies, mostly social services or non-statutory agencies.

poisoning in the future is less arbitrary than it has been for the past three decades.

We thank hospital staff at all four centres for their help with data collection, and Dr David Owens and an anonymous referee for their comments on earlier drafts of this paper.

Contributors: NK helped with the study design, collected and analysed all data, and contributed to writing the initial draft of the paper. $\mathrm{AH}$ helped to design the study and contributed to writing the initial draft of the paper. FC, EF, TF, and EG contributed to final aspects of study design, helped collect data, and commented on drafts of the paper. NK and $\mathrm{AH}$ are guarantors for the study.

Funding: This study was funded by the Medical Research Council, grant number G9533540, to AH, FC, Professor K Hawton, and Professor M Williams. At the time of this study NK was supported by the Medical Research Council and Leeds Community Mental Health Trust. Conflict of interest: None.

1 Hawton K, Fagg J, Simkin S, Bale E, Bond A. Attempted suicide in Oxford 1995. Oxford: University Department of Psychiatry, 1996.

2 Hawton K, Fagg J. Suicide and other causes of death following attempted suicide. Br J Psychiatry 1988;152:359-66.

3 Hawton K, James R. General hospital services for attempted suicide patients: a survey in one region. Health Trends 1995;27(1):18-21.

4 Department of Health and Social Security. The management of deliberate self-harm. London: Department of Health and Social Security 1984 (HN(84)25.)

5 House A, Owens D, Storer D. Psycho-social intervention following attempted suicide: is there a case for better services? Int Rev Psychiatry 1992;4:15-22.

(Accepted 23 September 1997)

\title{
Survival rates from interval cancer in NHS breast screening programme
}

\author{
Stuart Collins, Ciaran B J Woodman, Anthony Threlfall, Pat Prior
}

Centre for Cancer Epidemiology, University of

Manchester, Christie Hospital

NHS Trust,

Manchester

M20 4QL

Stuart Collins,

information scientist

Ciaran BJ

Woodman,

professor of public

health and cancer

epidemiology

Anthony Threlfall,

research officer

Pat Prior,

research fellow

Correspondence to: Mr Collins

BMJ 1998;316:832-3
The NHS breast screening programme invites women aged 50-64 for screening every 3 years. In this programme the term interval cancer is applied to a breast cancer occurring within 3 years of a screening test with negative results. Substantially higher than anticipated rates of interval cancers have already been reported from the NHS breast screening programme, ${ }^{12}$ and there is conflicting evidence on whether the survival rates of women with interval cancers are different from those of women with breast cancer occurring in an unscreened population. ${ }^{34}$ Were interval cancers to have a worse prognosis than cancers in an unscreened population, the reduction in mortality from breast cancer in the screened population might be substantially less than predicted.

To interpret survival estimates for women with interval cancers requires identification of a suitable group of unscreened women for comparison. In the context of a national screening programme this is difficult. Women who do not respond to an invitation for screening, for example, have been shown to have a worse outcome than unscreened women and are therefore unsuitable. ${ }^{4}$ The use of historical controls may also be inappropriate because of recent advances in managing breast cancer. Fortuitously, the phased introduction of the NHS screening programme in the north west has resulted in a group of women with breast cancer who lived in areas where screening had yet to be introduced whose survival can be compared with that of women diagnosed with interval cancers during the same calendar period. We report for the first time survival rates for interval cancers diagnosed during 1988-91 in the NHS breast screening programme. 


\section{Subjects, methods, and results}

The NHS breast screening programme in the north west started in 1988 and by 1991 was under way in 14 district health authorities. Women resident in the five remaining districts in the region were not invited for screening before 1991 and form the control population. We identified all invasive interval cancers diagnosed between 1988 and 1991, using published methods. ${ }^{1}$ We identified breast cancers presenting during this period in women aged 50-67 years in the control population from records held by the regional cancer registry. We determined date of death from data routinely notified to the registry. We calculated estimates of relative survival over five years and made comparisons using an appropriate proportional hazards regression that controlled for age. ${ }^{5}$

Seventy three interval cancers and 565 cancers from the control population were diagnosed during the study period. No significant difference could be shown between the relative survival rates of women from the control population with breast cancer and those of women presenting with interval cancers during the same period (hazards ratio 0.81 (95\% confidence interval 0.50 to 1.31$), \chi=0.67, \mathrm{df}=1, \mathrm{P}=0.41$ ). The robustness of this result is supported by the analysis of a further 441 interval cancers diagnosed after 1991, which showed a survival curve similar to that based on the 73 cancers (figure).

\section{Comment}

Although our results suggest no difference between the survival rates of women with interval cancers and those of women from the control population, variations in the quality of care provided for women from the two distinct areas could have invalidated this comparison. However, an analysis of survival rates for breast cancer, undertaken for the period immediately before the introduction of the screening programme in the north west, showed no significant differences when women were grouped according to their district of residence. It is reassuring that breast screening has not been detrimental to the survival of those women who presented with an interval cancer in the NHS screening programme. However, minimising the occurrence of interval cancers must remain a high priority if substantial reductions in mortality are to be achieved.

Contributors: SC participated in the discussion of core ideas and in identifying the study population, carried out data

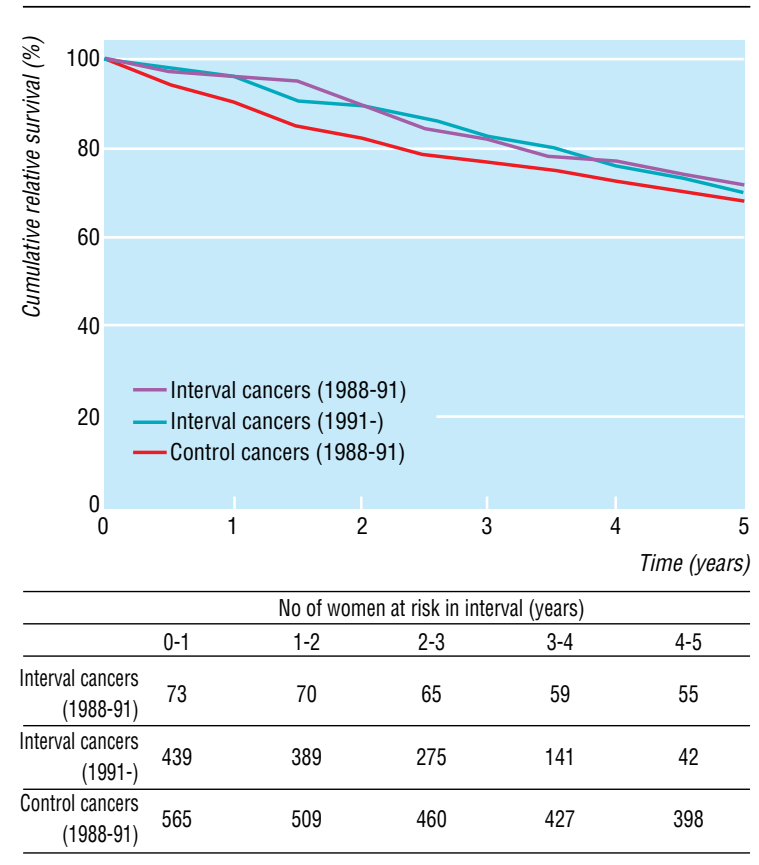

Relative survival rates for women with interval cancers and women with breast cancer in control group

verification, undertook the survival analyses and interpretation of the results, and contributed to writing the paper. CBJW initiated and coordinated the research, participated in the discussion of core ideas, helped in interpreting the results, and contributed to the writing of the paper. AT initiated the research, participated in the discussion of core ideas, identified and collated data on the study population, and contributed to the writing of the paper. PP participated in the discussion of core ideas, helped in interpreting the results and contributed to the writing of the paper. All authors are guarantors for the study.

Funding: None.

Conflict of interest: None.

1 Woodman CBJ, Threlfall AG, Boggis CRM, Prior P. Is the three year breast screening interval too long? Occurrence of interval cancers in NHS breast screening programme's north western region. BMJ 1995;310:224-6.

2 Day N, McCann J, Camilleri-Ferrante C, Britton P, Hurst G, Cush S, et al. Monitoring interval cancers in breast screening programmes: the East Anglian experience. J Med Screening 1995;2:180-5.

3 Andersson I, Aspegren K, Janzon L, Landberg T, Lindholm K, Linell F, et al. Mammographic screening and mortality from breast cancer: the Malmo mammographic screening trial. BMJ 1988;297:943-8.

4 Tabar L, Faggerberg G, Duffy SW, Day NE, Gad A, Grontoft O. Update of the Swedish two-county program of mammographic screening for breast cancer. Radiol Clin North Am 1992;30:187-210.

5 Hakulinen T, Abeywickrama KH. A computer program package for relative survival analysis. Computer Programs in Biomedicine 1985;19:197-207. (Accepted 22 October 1997)

\section{One hundred years ago Wanted: brains}

Dr Burt G Wilder, Professor of Physiology on the Cornell Staff of Instruction at Ithaca, has recently issued a circular asking prominent men in the United States to bequeath their brains to the university. He says that while it is easy to procure the brains of criminals and of insane or ignorant persons, it has hitherto been extremely difficult to obtain those of persons in whom the cerebral development is beyond the average. He adds that it is highly desirable for the advancement of science that a considerable number of brains of this character should be secured. This request, which has been circulated principally among the students and graduates of Cornell, is accompanied by a blank form of bequest, which, however, contains a clause by which the legacy becomes void if serious objection is made by the relatives of the deceased. (BMJ 1898;ii:1359) 